\title{
THE USE OF HALOTHANE ANAESTHESIA TO CONTROL AUTONOMIC HYPERREFLEXIA DURING TRANS-URETHRAL SURGERY IN SPINAL CORD INJURY PATIENTS
}

\author{
By J. D. Alderson, F.F.A.R.C.S.(I) and D. G. Thomas, F.R.C.S. \\ Spinal Injuries Unit, Lodge Moor Hospital, Sheffield
}

Abstract. Forty-five spinal cord injury patients undergoing trans-urethral surgery were anaesthetised using a mixture of nitrous oxide and halothane in oxygen. The use of halothane to control the hypertensive manifestations of surgically induced autonomic hyperreflexia is discussed.

\section{INTRODUCTION}

SPINAL cord transection above the fifth dorsal cord segment may lead to the development of a labile autonomic nervous system. Following the initial period of 'spinal' shock', the return of reflex activity in the intact but isolated cord segments leads to massive rather than local responses. Cord transection in the cervical or upper dorsal area removes the thoraco-lumbar sympathetic outflow from the influence of higher centre control. Afferent stimulation (particular visceral distension) via the isolated intact cord segments below the level of the lesion may lead to massive sympathetic nervous activity.

Symptoms of sympathetic overactivity have long been recognised both in animal experiments and in man (Sherrington, I897; Head \& Riddoch, I917; André Thomas, I92I; Watkins, I938). Head and Riddoch (I9I7) reported excessive reflex sweating and André Thomas (I92I) was concerned with the pilo-erection responses in paraplegic soldiers during the First World War. Guttmann and Whitteridge (1947) described in detail the whole symptomatology in particular the cardiovascular responses in paraplegics and tetraplegics such as flushing of the face, bradycardia, cardiac arythmias and vascular hypertension as the result of visceral hyperactivity. Elevation of blood pressure may cause retinal haemorrhages, and fatalities from cerebral haemorrhages have been reported (Kurnick, 1956). In a review of 300 spinal cord injury patients, I2 patients with neurological lesions between $\mathrm{C} 6$ and $\mathrm{T} 2$ demonstrated a rise of systolic blood pressure of $80-120 \mathrm{~mm}$. $\mathrm{Hg}$, in response to bladder distension. Cardiac irregularities occurred in 75 per cent of these patients (Kendrick, Scott, Jousse \& Botherell, 1953). Urethral instrumentation and bladder distension during trans-urethral surgery may well result in the production of autonomic hyperreflexia in patients with high cord lesions.

Varied techniques have been used to reduce the sympathetic overactivity. Gilberts et al. (1954) have described the effect of various anaesthetics on a group of spinal cord injury patients. The indications for general anaesthesia were:

I The control of spasm.

2. Open discussion of patient problems was possible.

3. Functional studies were facilitated.

4. Patients themselves had requested a general anaesthetic. 
The patients were divided into two groups according to the level of the lesion (Group I-above D5. Group 2-below D5). In 42.5 per cent of patients in Group I there was an elevation of blood pressure of greater than $50 \mathrm{~mm}$. $\mathrm{Hg}$, whereas in Group 2 only 3.9 per cent of patients showed an elevation in blood pressure. They also reported that spinal anaesthesia completely prevented autonomic hyperreflexia.

The use of spinal anaesthesia in spinal cord injury patients is a contraversial subject, with some workers feeling that it is contra-indicated (Drinker \& Helrich, 1963; Desmond, 1970).

The use of relaxant anaesthesia with tubocurarine and nitrous oxide with oxygen and intermittent positive pressure ventilation (I.P.P.V.) as a means of providing satisfactory autonomic control has been reported by Hassan (1974).

Drinker and Helrich (1963) reported the use of inhaled halothane to control autonomic hyperreflexia in one case and recommended its further consideration as a useful technique.

This paper presents the results of the use of halothane in 45 spinal cord injury patients undergoing trans-urethral surgery.

\section{PATIENTS STUDIED}

Forty-five male spinal cord injury patients were anaesthetised. Their ages ranged from 15 to 70 years. Twenty-four of these had cervical cord damage. Anaesthesia and surgery was performed from three months to I I years after injury.

\section{ANAESTHETIC METHOD}

a. Preoperative Assessment. This included a full cardio-vascular examination including a resting blood pressure recording. Prior to the inducation of anaesthesia the resting pulse rate and systolic blood pressure were recorded.

b. Pre-medication. Twenty-two patients received pethedine (50-100 mg.) with atropine $(0.6 \mathrm{mg}$.). Three patients received atropine $(0.6 \mathrm{mg}$.) only. Twenty patients received no pre-medication.

c. Induction. A sleep dose of sodium thiopentone was injected intravenously.

d. Maintenance. The intravenous induction was followed by inhalational anaesthesia using nitrous oxide, oxygen and halothane delivered via a face mask through a Magill circuit and this was continued throughout the operation. The halothane concentration for surgery was kept at $\mathbf{I} \cdot 5$ per cent in a mixture of approximately 30 per cent oxygen in nitrous oxide and only adjusted if blood pressure readings altered. If the systolic blood pressure rose above $160 \mathrm{~mm}$. $\mathrm{Hg}$, the halothane concentration was increased, and if the systolic pressure fell below $80 \mathrm{~mm} . \mathrm{Hg}$, the concentration was reduced.

An intravenous line was inserted using Ringer lactate solution prior to surgery.

e. Monitoring. Repeated systolic blood pressure monitoring was performed during the induction and maintenance stage of anaesthesia. This was measured by radial artery palpation during deflation of the sphygmomanometer cuff for ease and recording of rapid changes of pressure. Electro-cardiographic monitoring was commenced before the patient was transferred to the operating table. Cardiac ventricular dysrhythmias were treated with intravenous practolol, given in $2 \mathrm{mg}$. increments. 
Prior to the end of surgery, $250 \mathrm{ml}$. of Mannitol (20 per cent) was given intravenously to promote a diuresis. Any blood loss of greater than an estimated ten per cent of blood volume was replaced with whole blood.

\section{RESULTS}

In $2 \mathrm{I}$ of the patients the systolic blood pressure during surgery rose above the preoperative readings. Nineteen of these patients had cervical cord injuries, one a lesion at $\mathrm{D}_{4}$, and one at $\mathrm{D} 6$.

The highest recorded rise of systolic pressure was $40 \mathrm{~mm}$. $\mathrm{Hg}$, but in no case did the systolic pressure rise above $160 \mathrm{~mm}$. $\mathrm{Hg}$, therefore a concentration of more than $I \cdot 5$ per cent of halothane was not exceeded during surgery.

In the 2 I patients showing an elevation in systolic blood pressure, cardiac dysrythmias occurred in 12 patients, all with cervical cord injuries. In one patient the cardiac dysrhythmias occurred during the bladder wash-out procedure at the end of the operation. The dysrhythmias observed included supraventricular and

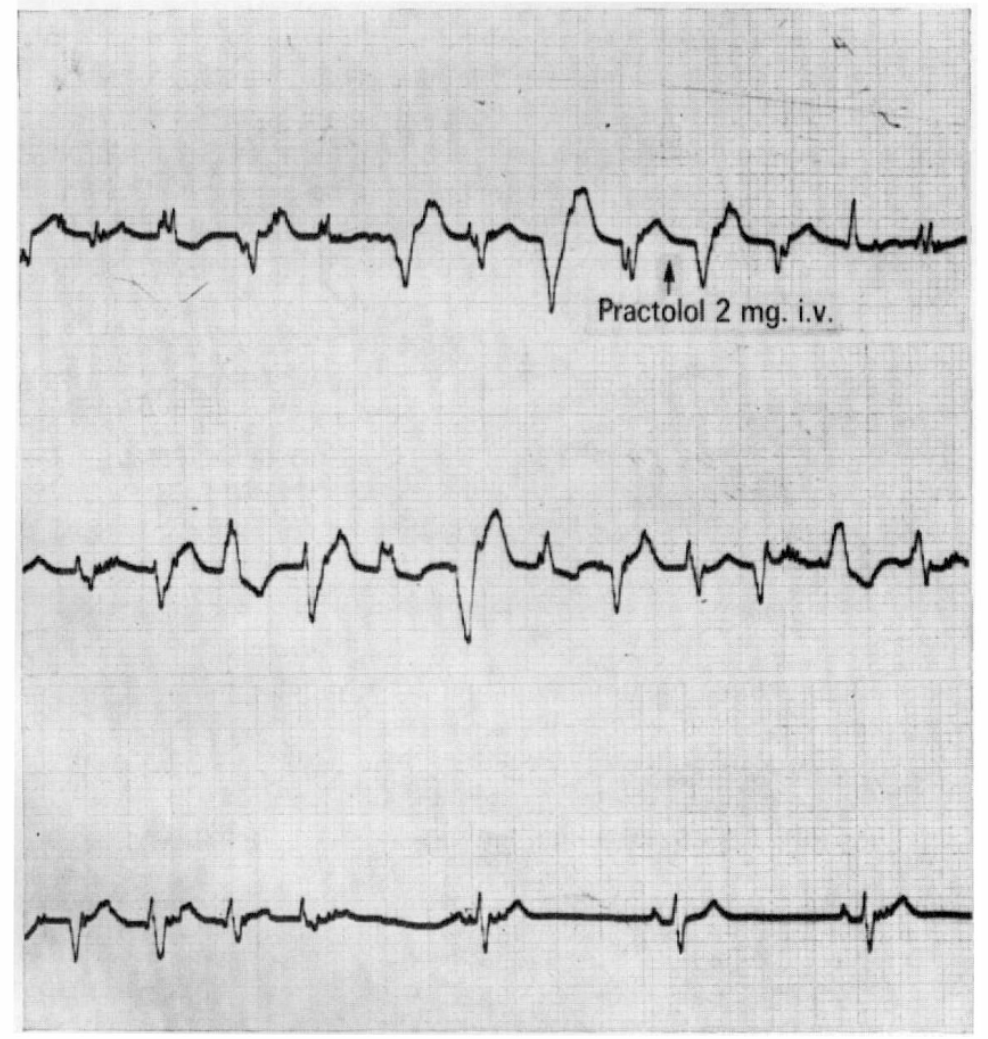

FIG. I

An E.C.G. taken during trans-urethral surgery in a male patient (age $2 \mathrm{I}$ ) with a complete C6 cord injury. The effect of intravenous practolol on cardiac dysrhythmia is shown. (Patient anaesthetised using nitrous oxide/halothane.) 


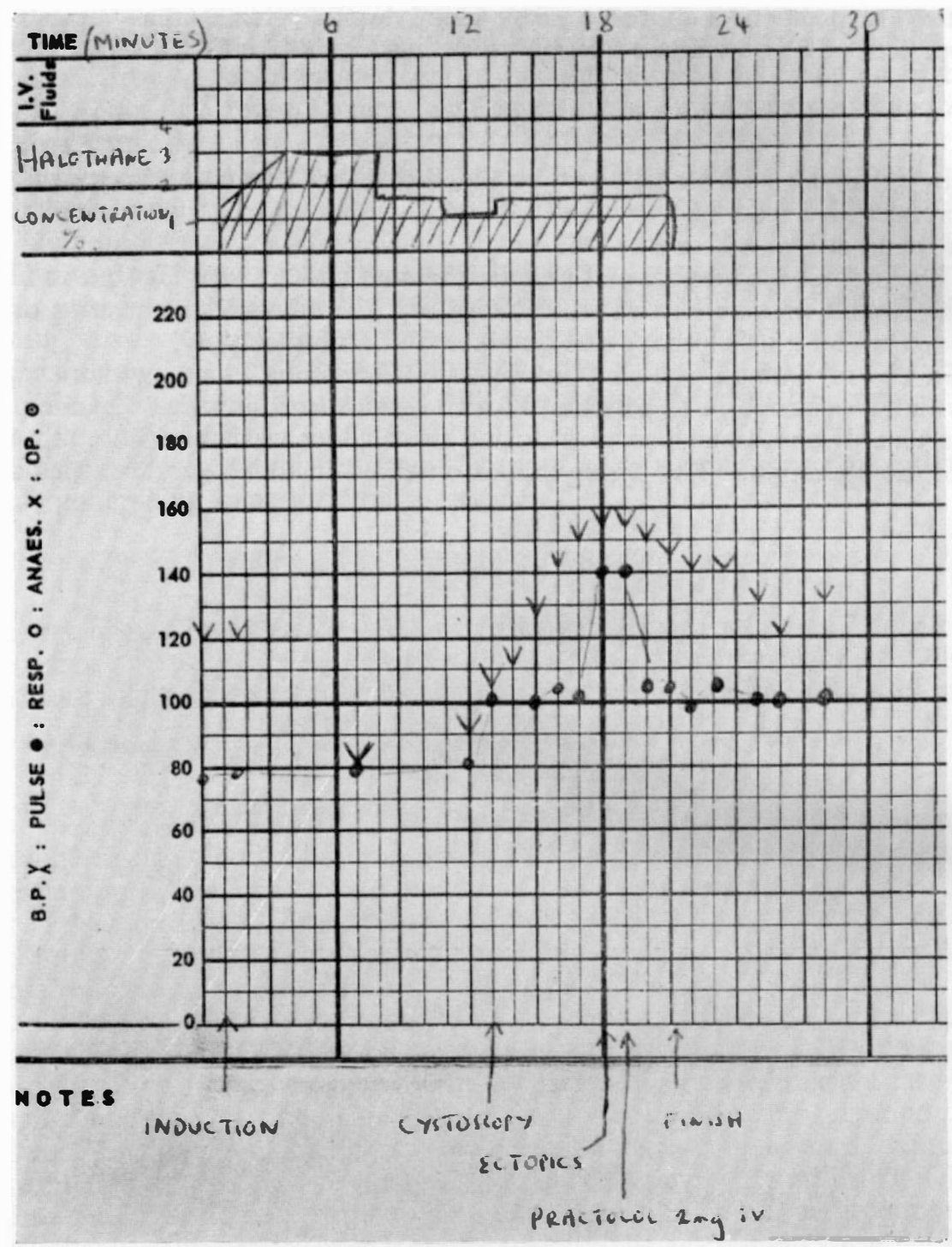

FIG. 2

The anaesthetic record chart of a 3I-year-old patient with C5-6 injury undergoing transurethral sphincterotomy under nitrous oxide/halothane anaesthesia.

ventricular ectopic activities producing irregular pulses. Seven of these 12 patients were given intravenous practolol in $2 \mathrm{mg}$. increments. In three patients sinus rhythm was restored after only $2 \mathrm{mg}$. of practolol. Two patients required $4 \mathrm{mg}$. and one patient $8 \mathrm{mg}$. before sinus rhythm was restored (fig. I). No other antidysrhythmic agent was used. 
Induction of anaesthesia with sodium thiopentone often resulted in a drop of systolic pressure by about $20 \mathrm{~mm}$. $\mathrm{Hg}$, but with the commencement of surgery the pressure was restored to the resting level or higher in the cervical group of patients.

The pulse rate characteristically increased upon induction with thiopentone before returning to preoperative values.

In six patients during surgery, it was necessary to administer intravenous propantheline (dose 5-1 5 mg.) to overcome increasing bladder spasm. Five of these six had cervical cord injuries and one had an injury at D6. Intravenous propantheline caused sinus tachycardia to develop but did not appear to alter the susceptibility to other cardiac dysrhythmias.

The total time of anaesthesia varied from 20 to 55 minutes, during which time the patients received from 0.5 to 2 litres of Ringer Lactate solution. Four of the 45 patients required a blood transfusion.

All the patients made an uneventful recovery and appeared to suffer no sequelae. Figure 2 shows a typical anaesthetic chart taken from a 3I-year-old male patient with a complete C6 injury.

\section{DISCUSSION}

Our results lend support to the published report that halothane can control the hypertensive manifestations of autonomic hyperreflexia during trans-urethral surgery (Drinker \& Helrich, I963). Cardiac dysrhythmias were observed but these responded well to intravenous practolol. The incidence of dysrhythmias in unanaesthetised patients with high cord lesions is known to be high (Kendrick et al., 1953). Halothane is known to increase the sensitivity of the heart to catecholamine induced dysrhythmias. (Raventós, 1956).

The success of halothane in controlling hypertensive episodes in spinal cord injury patients is not understood. The hypotensive effect of halothane in neurologically normal patients is thought to be due to several components, including sympathetic blockade (Raventós, I956), central vasomotor depression (Burn, I957), myocardial depression (Bloodwell et al., I96I; Morrow \& Morrow, 196I) and depression of smooth muscle of blood vessels (Burn et al., 1959).

Gersh et al. (1970) believe the main component to be a myocardial depressant effect and some workers believe that further increase of peripheral resistance may put such a depressed myocardium into ventricular failure (Prys-Roberts, I97I). If such work is applicable to patients with autonomic hyperreflexia the myocardial depressant action of halothane may significantly reduce cardiac output. No measurement of cardiac output was performed in this reported series. However, none of our patients showed any postoperative sequelae suggesting poor cardiac function during surgery. The duration of anaesthesia was so short that any myocardial depressant activity present was insufficient to cause problems.

The myocardial depressant effect of halothane is known to be further increased by the addition of $\beta$ receptor blockade (Stephen et al., I97I), but in none of our patients requiring practolol were there any postoperative problems.

\section{SUMMARY}

Halothane anaesthesia has been found useful in the control of hypertension from autonomic hyperreflexia during trans-urethral surgery. Cardiac dysrhythmias 
still remain a problem. This technique has the advantage of being well within the capability of the average anaesthetist.

\section{RÉSUMÉ}

Halothane anaethesia est trouvé utile dans le controle de hypertension de la hyperflexie autonomic pendant les opération trans-urethral. Le cardiac dysrhythmies reste toujours un problème. Cette technique a l'avantage d'ête dans la capacité de l'anaethetist moyen.

\section{ZUSAMMENFASSUNG}

Halothane Anaesthesie wurde als nützlich für die Kontrolle von Hypertension als Folge von autonomer Hyperreflexie während trans-urethraler Chirurgie gefunden. Herzarhtmetrie ist aber immer noch ein Problem. Diese Technik hat den Vorteil innerhalb der Kapabilität eines durchschnittlichen Anaesthetist zu sein.

\section{REFERENCES}

Bloodwell, R. D., Brown, R. C., Christenson, G. R., Goldberg, L. I. \& Morrow, A. G. (I96I). The effect of fluothane on myocardial contractile forces in man. Anaesthesia and Analgesia, 40, 352.

Burn, J. H., Epstein, H. G., Feigon, G. A. \& Paton, W. D. M. (I957). Some pharmacological actions of fluothane. Brit. Med. F. 2, 479.

Burn, J. H. \& Epstein, H. G. (I959). Hypofension due to halothane. Brit. F. Anaesth. 31, I99.

DEsmOND, J. (1970). Paraplegia. Problems confronting the anaesthesiologist. Canad. Anaesth. Soc. F. I7, 5, 435.

DRINKER, A. S. \& HELRICH, M. (I963). Halothane anaesthesia in the paraplegic patient. Anesthesiology, 24, 399.

Gersh, B. J., Prys-Roberts, C., Reuben, S. R. \& Baker, A. R. (I970). The relationship between depressed myocardial contractility and the stroke volume of the canine heart during halothane anaesthesia. Brit. F. Anaesth. 42, 560.

Gilberts, B. J., GoldFEIN, J. \& Rovenstine, E. A. (I954). Hypertension during anaesthesia in patients with spinal cord injuries. Anesthesiology, 1 5, 273.

GutTMANN, L. \& WhitTERoDGE, D. (I947). Effects of bladder distension on autonomic medanismis after spinal cord injuries. Brain, 70, 36.

Hassan, H. G. (1974). Anaesthesia in paraplegic patients. Anaesthesia, 29, 7, 629.

HEAD, H. \& REDDOCH, G. (I9I7). The automatic bladder, excessive sweating and some other reflex conditions in gross injury of the spinal cord. Brain, 40, I88.

Kenderick, W. W., Scott, J. W., Jousse, A. T. \& Botterell, E. H. (I953). Reflex sweating and hypertension in traumatic transverse myelitis. Treatment Serv. Bull. (Ottawa), 8, 437.

KURNICK, N. B. (I956). Autonomic hyperreflexia and its control in patients with spinal cord lesions. Ann. Inter. Med. 44, 678.

Morrow, D. H. \& MorRow, A. G. (I96I). The effects of halothane on myocardial contractile force and vascular resistance. Anesthesiology, 22, 537.

Prys-Roberts, C., Meloch, R. \& FoËx, P. (I97I). Studies of anaesthesia in relation to hypertension. I. Cardiovascular responses of treated and untreated patients. Brit. $\mathcal{F}$. Anaesth. 43, I22.

Raventós, J. (I956). The action of fluothane. A new volatile anaesthetic. Brit. $\mathcal{F}$. Pharmacol. II, 395.

Sherrington, Sir Charles (1897). The central nervous system. In $A$ Textbook of Physiology, Foster (ed.). Macmillan, London.

Stephen, G. W., Davie, I. T. \& Scott, D. B. (I97I). Haemodynamic effects of betareceptor blocking drugs during nitrous oxide/halothane anaesthesia. Brit. F. Anaesth. 43, 320.

TALAAT, M. (1937). Afferent impulses in the nerves supplying the urinary bladder. F. Physiol. 89, I.

Thomas, A. (I92I). Le Reflèxe Pilomoteur. Masson, Paris. 